Review

\title{
Nasa Selects Concepts for a New Mission to Titan, the Moon of Saturn
}

\author{
${ }^{1}$ Relly Victoria Petrescu, ${ }^{2}$ Raffaella Aversa, ${ }^{2}$ Antonio Apicella and ${ }^{1}$ Florian Ion Tiberiu Petrescu \\ ${ }^{1}$ ARoTMM-IFToMM, Bucharest Polytechnic University, Bucharest, (CE), Romania \\ ${ }^{2}$ Department of Architecture and Industrial Design, Advanced Material Lab, \\ Second University of Naples, 81031 Aversa (CE), Italy
}

Article history

Received: 08-01-2018

Revised: 11-01-2018

Accepted: 17-01-2018

Corresponding Author: Florian Ion Tiberiu Petrescu ARoTMM-IFToMM, Bucharest Polytechnic University, Bucharest, (CE), Romania E-mail: scipub02@gmail.com
Abstract: Nasa just has selected two new concepts for some new robotic missions, one of which aims to explore potential landing sites on Saturn's largest moon, Titan. This first concept is named Dragonfly, which is a dronelike rotorcraft that would use the environment on Titan to fly to a number of locations to sample materials and determine surface composition to examine Titan's organic chemistry and habitability. It also intends to monitor atmospheric and surface conditions as well as image landforms to evaluate geological processes and perform seismic studies. Titanium (or Saturn VI) is Saturn's largest satellite. This is the only known natural satellite that has a dense atmosphere and the only heavenly body, other than the Earth, for which there is clear evidence that it has a liquid surface and an atmosphere. Although the atmosphere on Titan does not seem to be similar to that of our planet, even at first sight very unfriendly, the fact that it exists, there is still a very important fact in our solar system, still a heavenly body with the atmosphere which urges us to start a serious research of this interesting heavenly body quickly. Titan is Saturn's sixth spheroidal satellite. Often described as a satellite-planet, Titan is about $50 \%$ larger than the Moon, the Earth's satellite and is $80 \%$ more massive. This is the second largest satellite in the Solar System, after Ganymede, Jupiter's satellite and is larger in volume than the smallest planet in the Solar System, Mercury, though only half as mass. The gravitational acceleration from the surface $(0.14 \mathrm{~g})$ is slightly lower than the monthly one $(0.17 \mathrm{~g})$. Titan was Saturn's first known satellite, discovered in 1655 by Dutch astronomer Christiaan Huygens and was the fifth satellite of a planet other than Earth that was discovered by humans. Titanium is mainly made of ice and rock water. As with Venus before the space era, the dense and opaque atmosphere prevented the study of Titan's surface. At present, there is enough information about the surface of the satellite since the arrival of the Cassini-Huygens mission in 2004, which also found liquid hydrocarbon varnishes in the polar regions of the satellite. The surface is geologically young, but several impact craters have also been discovered. The surface contains more mountains and a few possible crioviers, but is generally smooth. There are sand dunes in the equator, where the "sand" consists of ice. Titan's atmosphere is largely composed of nitrogen in gaseous form; other minor components leading to the formation of methane and ethane clouds and nitrogen-rich organic smog. Climate change, including wind and rain, creates features similar to those of the Earth's surface, such as sand dunes, rivers, lakes, seas (probably methane and liquid) and delta and is dominated by seasonal weather patterns similar to on Earth. With its liquids (both surface and underground) and the robust nitrogen atmosphere, the methane cycle on Titan is considered to be similar to the cycle of water on Earth, but at a much lower temperature.

Keywords: NASA, Robotic Missions, Titan, Organic Chemistry 


\section{Introduction}

Nasa just has selected two new concepts for some new robotic missions, one of which aims to explore potential landing sites on Saturn's largest moon, Titan (Aerospace, Technology, 2017).

This first concept is named Dragonfly, which is a drone-like rotorcraft that would use the environment on Titan to fly to a number of locations to sample materials and determine surface composition to examine Titan's organic chemistry and habitability.

It also intends to monitor atmospheric and surface conditions as well as image landforms to evaluate geological processes and perform seismic studies.

The second new concept, Comet Astrobiology Exploration Sample Return (CAESAR), aims to return a sample from 67P/Churyumov-Gerasimenko comet to determine its origin and history.

Selected from a set of 12 proposals, both the concepts are expected to be launched in a mission by the mid-2020s.

The proposals were submitted in April as part of Nasa's New Frontiers programme.

Nasa Science Mission Directorate associate administrator Thomas Zurbuchen said: "This is a giant leap forward in developing our next bold mission of science discovery.

"These are tantalizing investigations that seek to answer some of the biggest questions in our solar system today."

Steve Squyres from Cornell University in Ithaca, New York, US, will lead the CAESAR mission, which will be managed by Nasa's Goddard Space Flight Center in Greenbelt, Maryland.

Titanium (or Saturn VI) is Saturn's largest satellite. This is the only known natural satellite that has a dense atmosphere and the only heavenly body, other than the Earth, for which there is clear evidence that it has a liquid surface and an atmosphere. Although the atmosphere on Titan does not seem to be similar to that of our planet, even at first sight very unfriendly, the fact that it exists, there is still a very important fact in our solar system, still a heavenly body with the atmosphere which urges us to start a serious research of this interesting heavenly body quickly.

Titan is Saturn's sixth spheroidal satellite. Often described as a satellite-planet, Titan is about $50 \%$ larger than the Moon, the Earth's satellite and is $80 \%$ more massive. This is the second largest satellite in the Solar System, after Ganymede, Jupiter's satellite and is larger in volume than the smallest planet in the Solar System, Mercury, though only half as mass. The gravitational acceleration from the surface $(0.14 \mathrm{~g})$ is slightly lower than the monthly one $(0.17 \mathrm{~g})$. Titan was Saturn's first known satellite, discovered in 1655 by Dutch astronomer Christiaan Huygens and was the fifth satellite of a planet other than Earth that was discovered by humans.

Titanium is mainly made of ice and rock water. As with Venus before the space era, the dense and opaque atmosphere prevented the study of Titan's surface. At present, there is enough information about the surface of the satellite since the arrival of the Cassini-Huygens mission in 2004, which also found liquid hydrocarbon varnishes in the polar regions of the satellite. The surface is geologically young, but several impact craters have also been discovered. The surface contains more mountains and a few possible crioviers, but is generally smooth. There are sand dunes in the equator, where the "sand" consists of ice.

Titan's atmosphere is largely composed of nitrogen in gaseous form; other minor components leading to the formation of methane and ethane clouds and nitrogenrich organic smog. Climate change, including wind and rain, creates features similar to those of the Earth's surface, such as sand dunes, rivers, lakes, seas (probably methane and liquid) and delta and is dominated by seasonal weather patterns similar to on Earth. With its liquids (both surface and underground) and the robust nitrogen atmosphere, the methane cycle on Titan is considered to be similar to the cycle of water on Earth, but at a much lower temperature.

It is believed that this satellite could be a possible host for an extraterrestrial microbial living or at least a prebiotic environment rich in complex organic chemistry with a possible underground liquid ocean that would serve as a biotic environment (Aversa et al., 2017a-e; 2016a-o; Berto et al., 2016a-d; Mirsayar et al., 2017; Petrescu and Petrescu, 2016a-c; 2013a-d; 2012a-d; 2011 a-b; Petrescu, 2016; 2012a-b; 2009; Petrescu and Calautit, 2016a-b; Petrescu et al., 2016a-c; Petrescu et al., 2017 a-1).

\section{Materials and Methods}

Titan (Fig. 1) was discovered on 25 March 1655 by Dutch astronomer Christiaan Huygens. Huygens was inspired by the discovery by Galileo Galilei of four satellites of the planet Jupiter in 1610 and improved its telescope construction technology. Christiaan, with the help of his brother Constantijn Huygens, Jr., began to build telescopes around 1650. Christiaan Huygens discovered this Saturn satellite with the first telescope they built (Williams, 1995).

He simply called it the Saturn Moon (or Saturn Luna, in Latin with the meaning of "Saturn's Moon") in his work published in 1655 by Saturn Luna Obsessive Nova. After Giovanni Domenico Cassini published his findings on four more satellites of Saturn between 1673 and 1686, astronomers began to refer to these as Titan or Saturn I to $\mathrm{V}$ (with Titan in the fourth position). Other early epithets for Titan include "a Saturn's usual satellite". Titanium is officially named Saturn VI because after the new discoveries of 1789 the numbering scheme was frozen to avoid any new confusion (Titan was baptized with numbers II, IV and VI). Many small satellites closer to Saturn have been discovered since then (Williams, 1995). 


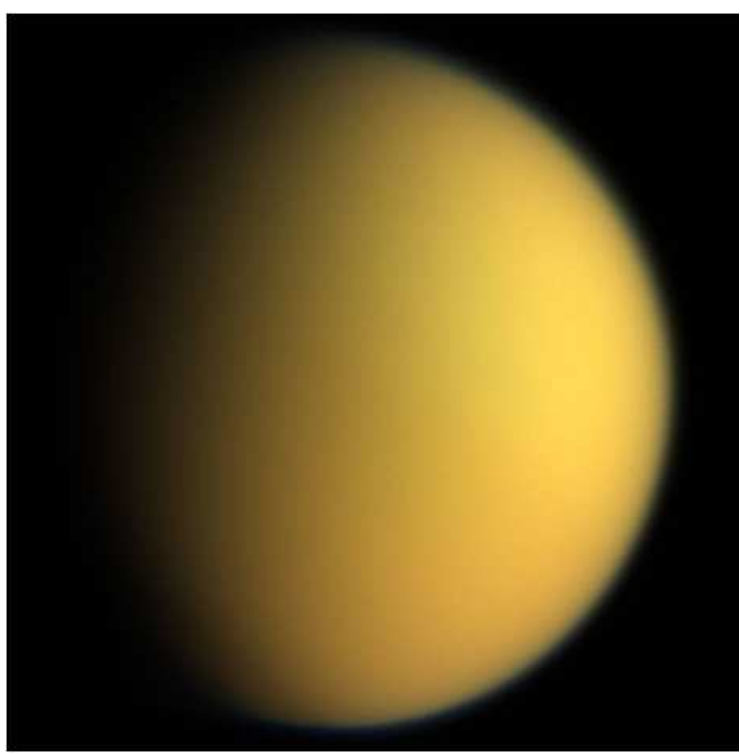

Fig. 1: PIA06230: Cassini's View of Titan: Natural color composite

The name Titan, like the names of all Saturn's seven known satellites at that time, was given by John Herschel (the son of William Herschel, who discovered Mimas and Enceladus) in his 1847 publication of the results of Astronomical Observations Made at the Cape of Good Hope (Williams, 1995).

He proposed the names of Mythological Titans (ancient Greek: Tzatan), the sisters and brothers of Cronos, who was called Saturn by the Romans. In Greek mythology, the Titans were a race of powerful deities, the sons of Uranus and Gaia, who reigned during the legendary Golden Age.

Titan revolves around Saturn every 15 days and $22 \mathrm{~h}$ of land. Like Earth's Moon and many other satellites of gas giants, its orbital period is identical to the period of rotation; Titan being locked tidal in synchronous rotation with Saturn and therefore always showing the same face to the planet. For this reason, there is a sub-saturday point on its surface where the planet Saturn seems to stand directly overhead. Longitude on Titan is measured west of the meridian passing through this point. Its orbital eccentricity is 0.0288 and the orbital plane is inclined 0.348 degrees relative to Saturn's equator. Viewed from Earth, the satellite has an angular distance of about 20 Saturn rays (about 1.2 million kilometers) to Saturn and subscribes a $0.8 \mathrm{sec}$ arc disc in diameter.

Titan is stuck in a 3: 4 orbital resonance with the small Hyperion satellite (Fig. 2) that has irregular shapes. A "slow and smooth" evolution through resonance in which Hyperion would have migrated from a chaotic orbit is considered unlikely, based on models. Hyperion was most likely formed from a stable orbital island, while the massive Titan absorbed or rejected the celestial bodies that approached him.

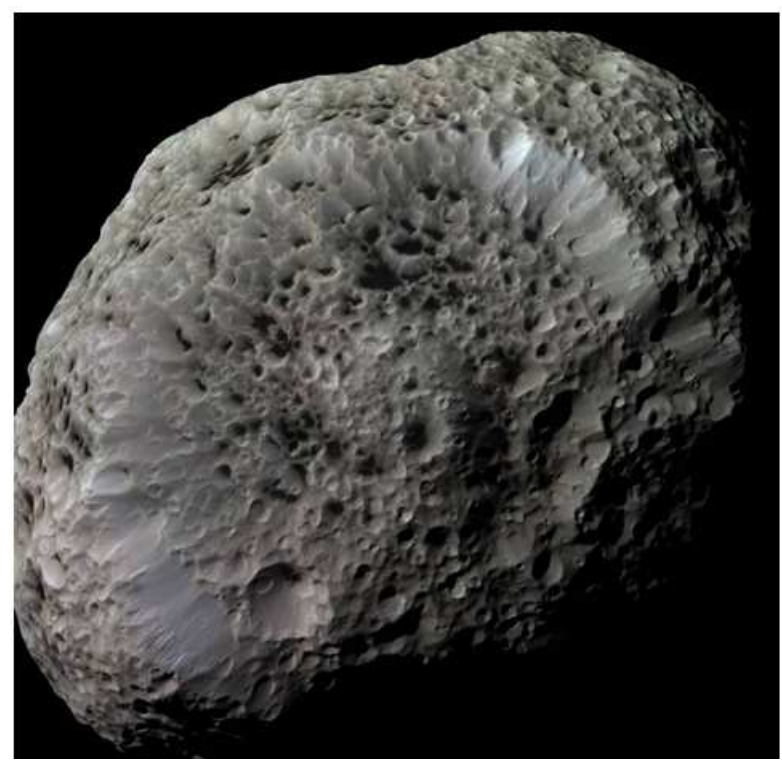

Fig. 2: Hyperion, also known as Saturn VII (7), is a moon of Saturn discovered by William Cranch Bond, George Phillips Bond and William Lassell in 1848

Titan has a diameter of $5,152 \mathrm{~km}$. For comparison, Mercury has a diameter of $4,879 \mathrm{~km}$, the Moon is 3,474 $\mathrm{km}$ and the Earth 12,742 km (Fig. 3). Before the arrival of the Voyager 1 spacecraft in 1980, Titan was thought to be slightly larger than Ganymede $(5,262 \mathrm{~km}$ in diameter) and hence the largest satellite in the Solar System; this overestimation was caused by Titan's dense and opaque atmosphere stretching several kilometers upward from its surface, increasing its apparent diameter. The diameter of Titan and its mass (and thus its density) are similar to those of Jupiter, Ganymede and Callisto's satellites. Based on its density of $1.88 \mathrm{~g} / \mathrm{cm} 3$, the composition of Titan is half frozen water and half rock. Although similar in composition to Dione and Enceladus, it is denser due to gravity compression.

Titanium is likely to be differentiated in several layers, with a $3.400 \mathrm{~km}$ rock center surrounded by several shells of different forms of ice crystallisation. Its interior may still be hot and it is possible to find there a layer of liquid, a kind of "magma" composed of water and ammonia between the crust of ice and deeper layers of ice created by the high pressure of the ice forms. The presence of ammonia allows water to remain in the liquid state even at low temperatures of $176 \mathrm{~K}\left(-97.15^{\circ} \mathrm{C}\right)$ (eutectic mixture with water). The existence of such an ocean was recently proven by the Cassini probe based on the existence of extremely low frequency radio waves in Titan's atmosphere. Titan's surface is considered to be a weak reflector of these radio waves, so they could be reflected by liquid ice from an underground ocean. Surface characteristics were systematically observed by the Cassini probe, which passed $30 \mathrm{~km}$ between October 2005 and May 2007, suggesting that the crust is decoupled from the inside, providing additional evidence for an inner fluid layer. 


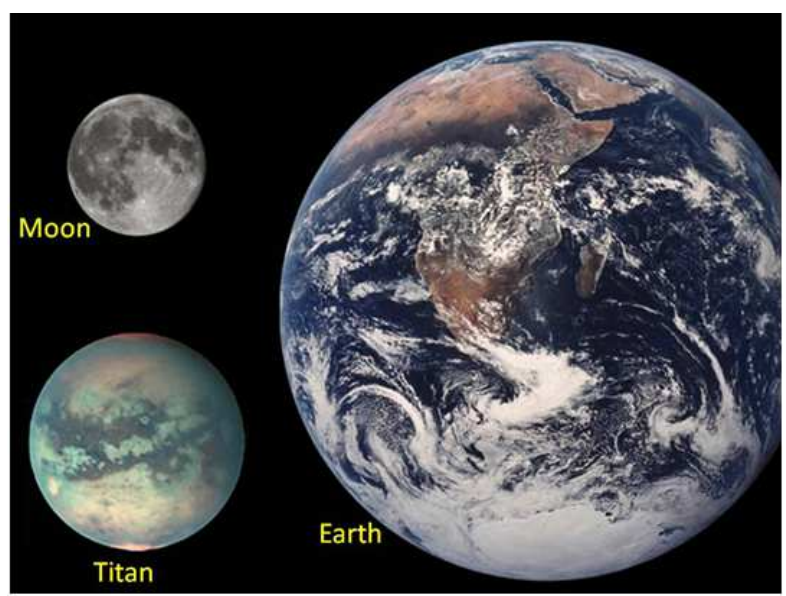

Fig. 3: A comparison of Titan, Earth and Moon

A study at the beginning of 2000 by the DLR Planetary Research Institute at Berlin-Adlershof placed Titan in a group of "big ice satellites" alongside Callisto and Ganymede.

\section{Results}

Titan is the only known satellite that has more than a trace of atmosphere. Observations of the Voyager space probes have shown that the atmosphere is denser than the Earth, with a surface pressure of about 1.45 times greater than that of the Earth. The atmosphere of the Titan satellite is about 1.19 times more massive than the Earth's total atmosphere. The atmosphere has opaque layers that block most of the light received from the Sun and other sources, which makes surface details not visible. The atmosphere is so thick and the gravity so low that people could fly through it by waving "wings" attached to their arms. The small gravity of the Titan makes the atmosphere more extensive than Earth's, even at a distance of $975 \mathrm{~km}$, the Cassini probe had to make adjustments to maintain a stable orbit against the atmospheric friction forces. Titan's atmosphere is opaque at many wavelengths and a full reflection spectrum of the surface is impossible to make from the outside. It was not realized until the arrival of the Cassini-Huygens mission in 2004, when the first direct images of Titan's surface were obtained. The Huygens probe was unable to detect the direction of the Sun during its descent and although it was able to take surface images, the technical team of the Huygens probe compared the process with "taking pictures in a parking lot at sunset".

Here is the time to stop short and discuss this very important issue. So to terrap a planet from our solar system or even from the outside of it, we need to start by creating the atmosphere. Mars's advantage is that it already contains the elements necessary to create the atmosphere of oxygen and hydrogen separated and they can be combined right there to create water on the planet and its atmosphere. Nitrogen, which has the role of atmospheric support, especially for oxygen and atmospheric water, is not found on Mars, so it will have to be created somewhat, which brings some technical difficulties to our current technologies, although they are still in need a future development. On Titan, there is already an atmosphere that contains Azot so that it will need oxygen and a certain amount of water to create an atmosphere identical to Earth. Both elements, oxygen and hydrogen are found in sufficient Titan quantities so we can massively introduce oxygen into Titan's atmosphere to turn it to the ground not by now with about $18-20 \%$ oxygen but at its initial level when oxygen was present in the Earth's atmosphere in massive quantities reaching about $28-30 \%$. Certainly there is already Titan frozen water, but we can also create oxygen and hydrogen for a certain amount to be introduced into the Titanic atmosphere.

The particular aspects of Titan's atmosphere give us a real exuberance that leads us to a possible terrain and colonization of the planet Titan (we can call it the planet, even if it is only a satellite because it has a remarkable dimension).

\section{Discussion}

The presence of a significant atmosphere was suspected by the Spanish astronomer Josep Comas Sola who observed a distinct dark Titan in 1903 and was confirmed by Gerard P. Kuiper in 1944 on the basis of a spectroscopic technique that estimated a partial atmospheric pressure methane in the order of 100 millibars $(10 \mathrm{kPa})$. Further observations in the 1970s showed that Kuiper's figures were significantly underestimated; the abundance of methane in Titan's atmosphere is ten times higher and the surface pressure is at least twice as high as predicted. The high surface pressure was an indication that methane could be just a small part of Titan's atmosphere. In 1981, Voyager 1 made the first detailed observations of Titan's atmosphere, showing that the surface pressure was higher than that of the Earth, having 1.5 bars. Titan's atmosphere is the densest and richest in nitrogen than the Solar System in the Solar System. The atmospheric composition in the stratosphere is $98.4 \%$ nitrogen, the rest of $1.6 \%$ being largely methane (1.4\%) and hydrogen $(0.1-0.2 \%)$. Since methane condenses into the atmosphere at high altitudes, its abundance rises with a decrease in height under tropopause at an altitude of 32 $\mathrm{km}$, stabilizing at a value of $4.9 \%$ between $8 \mathrm{~km}$ and its surface. There are traces of other hydrocarbons such as traces of ethane, diacetylene, methylacetylene, acetylene and propane, but also other gases such as argon, cyanoacetylene, hydrogen cyanide, carbon dioxide, cyanogen and helium. The orange color, as it 
appears from the cosmic space, may be due to other chemical complexes in small amounts, possibly tolls, organic precipitations like the tar. It is believed that hydrocarbons appear in the upper atmosphere as a result of the reactions resulting from methane dissipation by ultraviolet light of the sun, producing a thick orange mist. The satellite does not have a magnetic field, although some studies in 2008 have shown that Titan has retained Saturn's magnetic field remnants in the short moments when it was out of the Saturn magnetosphere when exposed directly to the solar wind. This field could ionize and carry some molecules at the tip of the atmosphere. In November 2007, scientists have discovered the presence of negative ions that have a mass of 10,000 times greater than the mass of hydrogen in Titan's ionosphere, they are believed to collapse in lower regions where they form the orange fog that makes the surface of the satellite invisible. Their structure is currently unknown, but is believed to be tholins and could be the basis for the appearance of more complex molecular structures, such as polycyclic aromatic hydrocarbons.

The energy received from the Sun would have to convert all methane traces from Titan's atmosphere into more complex hydrocarbons over the last 50 million years (a short period compared to the age of the Solar System). This suggests that methane is replenished somehow from a surface reservoir or within the Titan satellite. Since Titan's atmosphere contains 1,000 times more methane than carbon monoxide (Fig. 4), significant contributions to comets are taken into account as comets are composed of carbon monoxide rather than methane. As the Titan satellite has captured some of the early Saturn nebula at the time of the Solar System, it does not seem possible, because in this case it should have a similar atmospheric abundance to the solar nebula, including hydrogen and neon. Many astronomers believe that the origin of the methane in Titan's atmosphere is the satellite itself, considering that the methane is released from the cryovulcanic eruptions. A possible biological origin of methane has not been ruled out.

There is also a pattern of air circulation that has been identified as following Titan's rotation direction from west to east. Observations of the atmosphere, made in 2004 by Cassini, suggest that Titan is also a "superspinner", similar to the Venus plant, having an atmosphere that rotates much faster than its surface.

The Ionosphere of the Titan satellite is much more complex than the Earth, with a main ionosphere at an altitude of 1,200 km, but it also has an additional particle cover loaded at an altitude of $63 \mathrm{~km}$. This makes the atmosphere divided into two chambers with different radio resonances. However, Titan's natural radio waves are unclear, as there does not seem to be an extensive luminous activity.

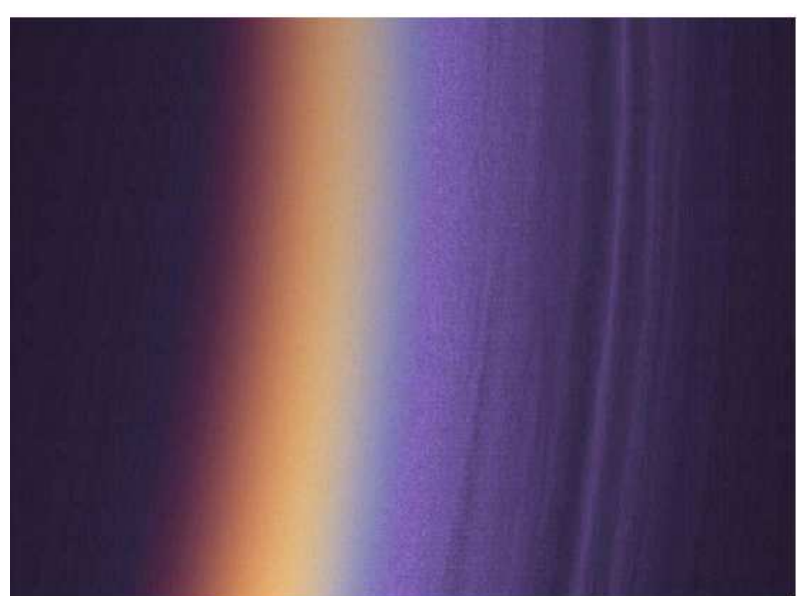

Fig. 4: The upper layers of the titan atmosphere

The surface temperature is about $94 \mathrm{~K}\left(-179^{\circ} \mathrm{C}\right.$, or $\left.290^{\circ} \mathrm{F}\right)$. At this temperature the frozen water does not evaporate, so the atmosphere is almost devoid of water vapor. The atmospheric fog contributes to the satellite's anti-greenhouse effect, reflecting sunlight back into space, making the surface significantly more cool than the upper atmosphere. The satellite receives only about $1 \%$ of the amount of sunlight the Earth receives.

Titan's clouds, perhaps composed of methane, ethane or other simple organic substances, are scattered and variable, sprinkled through the surrounding fog. This atmospheric methane creates a surface greenhouse effect, without which Titan would be much colder. The findings of the Huygens probe indicate the presence of periodic rainfall of liquid methane and other organic compounds that wet the surface of the satellite. In October 2007, observers noted an increase in the apparent opacity of the clouds above the Xanadu equatorial region, a kind of "methane drift", although this is not a direct proof of the existence of the rain. Still, images of southern hemisphere lakes that have been captured for a year show that they have grown and that they have been fueled by seasonal hydrocarbon rainfall. It is possible that the surface areas are covered with a layer of tolins, but this has not been confirmed. The presence of rain would indicate that Titan is the only heavenly body other than the Earth on which the rainbow could form. However, given the extreme opacity of the atmosphere in visible light, the vast majority of rainbows would only be visible in the infrared.

Simulations of global wind models, based on wind speed information from the Huygens probe, suggested that Titan's atmosphere is circulating in a single Hadley cell. The warm air rises to the southern hemisphere which led to a "summers" experiment when Huygens descended. Warm air sinks into the northern hemisphere, resulting in high-altitude air flows from south to north and low-air currents from north to south. Such an enormous Hadley cell is only possible in a slow rotation 
world like Titan. Polar-to-pole cell wind traffic seems to be centered on the stratosphere, with simulations suggesting the possibility of change every 12 years, with a period of three years of transition, over a Titanian year (over 30 terrestrial years). This Hadley cell creates a low-pressure global band as a terrestrial effect of the variation of the intertropical convergence zone. Unlike Terra where the oceans are limited in this area to the tropics, the Titan, the area traverses the distance between the two poles, carrying rain clouds with it. This makes Titan, despite the low temperatures, have a tropical climate.

The number of methane lakes visible near the southern pole is less than the number of lakes near the north pole. Because the southern pole is currently in the summer and the North Pole in the winter, a hypothesis would be that methane rains appear in winter poles and methane evaporates in the summer.

In September 2006, Cassini photographed a large cloud at a height of $40 \mathrm{~km}$ above the north pole. Although it was known that methane is to be condensed in the atmosphere of Titan, the cloud was suspected of containing ethane, due to the size of the particles was detected only 1-3 micrometers and ethane can also freeze at these altitudes. In December, Cassini again spotted the cloud cover and detected methane, ethane and other organic compounds. The cloud was over $2400 \mathrm{~km}$ in diameter and was still visible over a month at a new passage of the space probe. One of the hypotheses is that it is currently raining (or, if cold enough, snowing) at the north pole; the falls from the northern polar latitudes being strong enough to bring organic particles to the surface. This was the strongest evidence for the hypothesis of the existence of the methane cycle on Titan (analogous to the cycle of water on Earth).

Clouds were also found above the southern polar region. While it usually covers only $1 \%$ of the Titanium disk, there have been noticed breakthroughs where the cloud cover expands quickly covering approx. $8 \%$ of Titan's disc. A hypothesis asserts that the clouds in the southern polar region are formed when the increased sunlight levels in summer bring them up into the atmosphere, resulting in convection. This explanation is complicated by the fact that the formation of clouds was observed not only after the summer solstice, but also in the middle of the spring. Methane humidity has increased in the South Pole, possibly contributing to the rapid increase in cloud size. There, in the southern hemisphere, it was summer until 2010, when Saturn's orbit, which controls the satellite movement, tilted the northern hemisphere towards the Sun. When seasons change, it is expected that ethane will begin to condense over the South Pole.

Research patterns that fit well with the observations made suggest that Titan clouds are grouped at their preferred coordinates and that the layer of clouds varies depending on the distance from the surface on different parts of the satellite. In polar regions (over 60 degrees latitude) large-scale permanent clouds of ethane appear higher in the troposphere. At lower latitudes, the main methane clouds are between 15 and $18 \mathrm{~km}$ and are sporadic and localized. In the hemisphere where the summer is usually, thick, but sporadic methane clouds appear to be grouping around $40^{\circ}$.

Ground observations have also highlighted the seasonal variations of clouds. During Saturn's 30-year orbit, the Titan clouds seem to be running for 25 years and then disappear for four to five years before re-enlivening.

Cassini also detected high-altitude white clouds of the Cirrus type in Titan's upper atmosphere, probably also made of methane.

Though there is no evidence of lightning on Titan, computer simulations suggest that clouds in the low troposphere of the satellite can accumulate in sufficient quantities to generate lightning at an altitude of about $20 \mathrm{~km}$.

The surface of Titan has been described as "complex, fluid and geologically transformed." The atmosphere is twice as thick as Earth's, making astronomical instruments difficult to capture images from the surface in the visible light spectrum. The Cassini spacecraft used infrared, altimeter and radar with a synthetic opening to make portions of the Titan map during its over satellite flights. The first images revealed a diverse geology with both harsh and smooth areas. There are features that seem to be of volcanic origin, which probably erupt water mixed with ammonia. There are also wrinkled features, some of which have hundreds of kilometers in length, which seem to be caused by wind blowing particles. The examination also showed that the surface is relatively smooth, with few objects that appear to be impact impacts that have been filled, probably due to hydrocarbon rainfall or volcanoes. Radar altimeter suggests that the height variation is reduced, usually no more than $150 \mathrm{~m}$. Occasional elevation changes of $500 \mathrm{~m}$ have been discovered and Titan has mountains that sometimes reach from several hundred meters to more than $1 \mathrm{~km}$ in height.

The surface of Titan is marked by large, bright and dark land areas. These include Xanadu, a vast, highly reflective equatorial area that is roughly the size of Australia. It was first identified in the infrared images of the Hubble Space Telescope in 1994 and was later observed by the Cassini probe. The region is full of hills and cut by valleys and gullies. It is traversed in several places with dark topographic features: sinuous alignments that resemble ridges or cracks. These may indicate a tectonic activity, proof that Xanadu is geologically young. Alternatively, the alignments can be liquid-formed channels, suggesting an old ground that has been cut through flow systems. There are dark areas of similar dimensions in other areas that have been observed from the ground and from Cassini. It has been speculated that these are methane or ethane, but Cassini's observations seem to indicate something else (Fig. 5).

The possibility of large hydrocarbon Titan was first suggested based on data obtained by Voyager 1 and 2 
have shown that titanium could have a thick atmosphere about a correct temperature and a composition necessary for the existence of such large hydrocarbon. Direct evidence was not obtained until 1995, when Hubble data and other observations suggested the existence of liquid methane on Titan either in disconnected pockets or on a general scale in the form of oceans similar to those on Earth.

The Cassini mission confirmed this hypothesis, though not immediately. When the probe arrived in the Saturn system in 2004, it was hoped that hydrocarbon lakes or oceans could be detected by the reflection of light from the surface of liquid bodies, but no specular reflection was initially observed. Near the southern pole a dark feature of the surface called Ontario Lacus was identified (and later confirmed as indeed a lake). A possible shoreline has also been identified near the south pole through radar images. After the flight of July 22, 2006, when the Cassini spacecraft's radar photographed the northern latitudes (which were in the winter), several large, smooth spots were observed pointing the surface near the pole. Based on observations, scientists announced in January 2007 that there are "definitive proofs of methane-filled lakes on Saturn's moon, Titan." The Cassini-Huygens team concluded that these features are almost certainly the longsought hydrocarbon lakes, the first stable liquid characteristics found outside the Earth's surface. Some of these seem to have associated liquid channels and are in topographical depressions. Generally, Cassini radar observations have shown that the lakes cover only a few percent of its surface and are concentrated near the poles, making Titanus much drier than the Earth.

In June 2008, Cassini's visual and infrared mapping spectrometer confirmed the presence of liquid gas beyond any doubt in Ontario Lacus. On December 21, 2008, Cassini walked directly over Ontario Lacus and noticed a reflection in the radar mirror which, being strong, saturated the receiver of the probe, indicating that the lake level does not vary by more than $3 \mathrm{~mm}$ (which implies either that the surface winds were minimal or the hydrocarbon fluid in the lake is viscous.

Speculative reflections are indicators of a smooth surface as a mirror, so this observation confirms the conclusion drawn from the radar images of the presence of a large body of liquid. The observation was made as soon as the northern polar region came out of the 15 years of dark winter.

On July 8, 2009, the VIMS instrument on Cassini saw a specular reflection of a smooth surface like a mirror, which today is called Jingpo Lacus, a lake in the northern polar region shortly after it left the 15-year area of dark and winter.

The radar measurements performed in July 2009 and January 2010 indicate that Ontario Lacus is extremely shallow, with an average depth of $0.4-3.2 \mathrm{~m}$ and a maximum depth of 2.9-7.4 m. In contrast, the hemisphere northern Ligeia Mare feature has depths of over $8 \mathrm{~m}$, being the maximum measurable radar instrument.

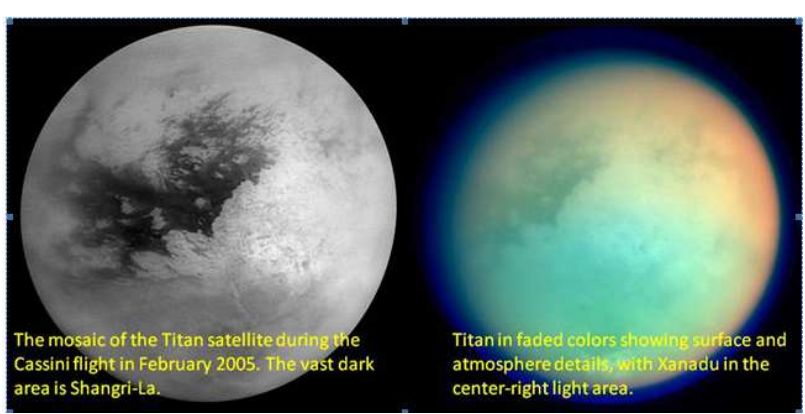

Fig. 5: This mosaic of Titan's surface was made from 16 images. The individual images have been specially processed to remove effects of Titan's hazy atmosphere and to improve the visibility of the surface near the terminator (the boundary between day and night). The images were taken with the Cassini spacecraft narrow-angle camera through a filter sensitive to wavelengths of polarized infrared light and were acquired at distances ranging from approximately 226,000 to 242,000 kilometers (140,000 to 150,000 miles) from Titan

The radar, SAR and Cassini-based images have discovered several impact craters on the surface of the Titan satellite, suggesting that this heavenly body is relatively young. The few uncovered impact craters include a $440 \mathrm{~km}$ two-mile ring called Menrva seen by the Cassini ISS as a concentric, dark-lighted model. Also, a smaller flat floor of a crater, $60 \mathrm{~km}$ wide, called Sinlap and a $30 \mathrm{~km}$ crater with a central peak and a dark floor called Ksa. Radar and Cassini images also revealed a series of "crateriforms," circular features of the surface that could be impacting but lacking certain features that would lead to accurate identification. For example, a brilliant 90-kilometer ring, known as Guabonito, was noticed by Cassini. This feature is considered to be an impact crater covered by dark sediments that have been blown by wind. Other similar features were observed in the dark regions of Shangri-La and Aaru. Through the radar, there were several circular features that can be craters in the Xanadu luminous region during Titan's overflight by Cassins on April 30, 2006.

Many craters or potential craters have evidence of extensive erosion and all show that they have undergone some changes (Fig. 6). Most large craters have stood together or have incomplete edges, despite the fact that some Titan craters have relatively more marginal edges than anywhere else in the Solar System. However, there is little evidence of palimpsest formation by relaxing the viscoelastic crusts unlike other large ice satellites. Most craters lack the central peaks and have smooth floors, possibly due to the impact or eruption of the late lava cryovulan. While filling from different geological processes is one of the reasons for the relative shortage of craters, atmospheric shields also play an important role; it is estimated that the atmosphere reduces the number of craters on its surface by a factor of two. 


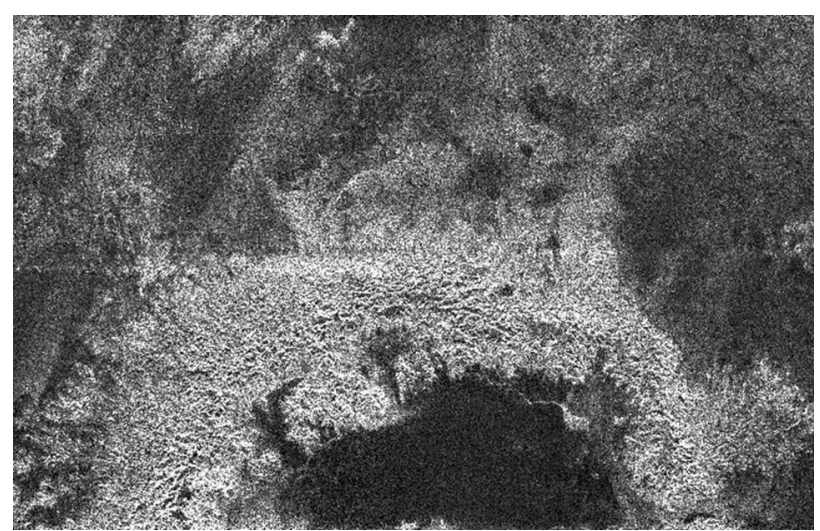

Fig. 6: The radar image of an impact crater on the surface of the Titan satellite, with a diameter of $139 \mathrm{~km}$ which shows a smooth floor, rough edge and eventually a central peak

The high resolution radar obtained in 2007 covered only $22 \%$ of the satellite surface, suggesting a number of non-uniformities in the distribution of its craters. Xanadu has craters 2-9 times more than elsewhere. The main hemisphere has a $30 \%$ greater density than the posterior hemisphere. Here there are lower densities of craters in equatorial dunes and in the northern polar region (where hydrocarbon lakes and seas are the most common).

Pre-Cassini models with impact and angle trajectories suggest that if an asteroid hits the crust of frozen water, a small amount of water from the impact remains liquid in the crater. It can persist for centuries or even more in the form of liquid, enough time for "the synthesis of simple molecules precursor to the origin of life."

Scientists have speculated that these conditions on Titan resemble the original ones on Earth, albeit at a much lower temperature. Detection in 2004 of argon 40 isotopes in the atmosphere indicated that volcanoes generated "lava" effluents composed of water and ammonia. Global maps of surface lakes distribution have revealed that there is not enough surface methane to explain the continued presence of methane in the atmosphere and therefore an important part has to be added through volcanic processes.

However, there are some surface features that can be interpreted unequivocally as being crippled. One of the first of these features discovered by Cassini radar observations in 2004, called Ganesa Macula, resembles the geographic features called "Pancake Domes" or "Farrum" found on Venus and originally thought to be originally cryovulcanic, although the American Geophysical Union rejected this hypothesis in December 2008. This feature was considered not to be a dome in its entirety but seems to be the result of accidental combinations of light and dark spots. In 2004 Cassini also detected an unusually bright element (called Tortola Facula), which was interpreted as a cryovulcanic dome. Other similar features have not been identified until 2010. In December 2008, astronomers announced the discovery in Titan's atmosphere of two transient "bright spots" of an unusually long duration that seem too persistent to be explained by simple patterns but the weather, suggesting that they were the result of extensive cryovulcanic episodes.

In March 2009 lava-like structures were observed in a region called the Orcus Hut, which seems to fluctuate as a luminosity for several months. Although several phenomena have been proposed as explanations of this fluctuation, lava flows began to rise $200 \mathrm{~m}$ above the surface confirming that they broke out of the surface.

A mountainous area $150 \mathrm{~km}$ long, $30 \mathrm{~km}$ wide and $1.5 \mathrm{~km}$ high was discovered by Cassini in 2006. This area is located in the southern hemisphere and is believed to be composed of frozen and snow-covered methane. The movement of the tectonic plates, probably influenced by a nearby impact pool, could create a hole through which the material of the mountain ascended. Prior to Cassini, scientists assumed that the topography of the topography would be impact structures, but these findings show that they are similar to those on Earth, the mountains being formed by geological processes.

In December 2010, the Cassini mission team announced the discovery of the most persuasive cowardice found so far. Called Sotra Facula, it is one of a chain of at least three mountains, each of which is 1000 to $1500 \mathrm{~m}$ high, some of which have large craters. The soil around them seems to be covered by leaked lava leaks.

If the volcanism on Titan really exists, the hypothesis is that it is determined by the energy released from the disintegration of the radioactive elements in the mantle, as it is on Earth (Fig. 7). Magma on Earth is made of liquid rock, which is less dense than the solid rocky crust through which it erupts. Because the ice is less dense than water, Titan's aqueous magma would be dense than crumbling solid ice. This means that the Titan cryovulanism would require a great deal of extra energy to function, possibly through the tidal deformation caused by the approaching Saturn.

In the early 2000s images of Titan's surface taken by Earth's telescopes there were large dark field regions stretching along the Titanic Equator. Prior to the arrival of the Cassini probe, it was considered that these regions would contain large amounts of organic matter such as tar or liquid hydrocarbons. The radar images captured by the Cassini probe have shown that these regions are extensive plains covered by longitudinal sand dunes up to $330 \mathrm{~m}$ high, a kilometer wide and from ten to hundreds of kilometers long. It is believed that longitudinal (or linear) dunes are formed by moderate variable winds batting either in one direction or alternately from two different directions. The dunes of this type are always aligned with the average wind direction. In the case of Titan, steady winds (east) combine with tidal variable winds (about $0.5 \mathrm{~m}$ per second). Tidal winds are the result of Saturn's attraction forces on Titan's atmosphere, forces that are 400 times 
more powerful than the tidal forces of the Moon on Earth and tend to lead the wind to the equator. This wind pattern causes sand dunes to build long parallel lines aligned from west to east. The dunes change their orientation to the mountains because the wind direction is changing as well.

Titan sand could have formed when liquid methane rained and eroded the base frozen rock, possibly in the form of torrential floods. Another alternative is that the sand could come from solid organic substances produced by the photochemical reactions in the atmosphere. May 2008 studies on the composition of the dunes showed that they had less water than the rest of the Titan satellite and probably originated from the aggregation of organic matter after it rained to the surface (Fig. 8).

The Miller-Urey experiment and several other experiments have shown that in an atmosphere similar to that of Titan, by the addition of ultraviolet radiation, complex molecules and polymeric substances such as tolls may appear. The reaction begins with the dissociation of nitrogen and methane, forming cyanide and acetylene hydrogen. Other reactions have been studied extensively.

In October 2010, Sarah Horst of Arizona University said she found five nucleotide bases - blocks of DNA and RNA construction - among the set of compounds that occurred when energy was applied in a combination of gases similar to those in Titan's atmosphere. Horst also found amino acids, which are the building blocks of proteins. Sarah Horst said it was the first time that nucleotide and amino acid bases were found in such an experiment without liquid water being present.

Laboratory simulations have led to the idea that Titan might have enough organic material to begin a chemical evolution analogous to Earth's. While analogy involves the presence of liquid water for a longer period than has been observed at present, some theories suggest that liquid water from an impact could be preserved under a frozen and isolated shell. It has also been noticed that the oceans of liquid ammonia could be deep under the surface; a model being that a solution of ammonia and water would be $200 \mathrm{~km}$ under the crust of frozen water, extreme conditions according to terrestrial standards but capable of ensuring the survival of Titan. The heat transfer between the inner and the top covers would be critical in sustaining life in an underground ocean. Detecting microbial life would depend on its biogenic effects. For example, consideration was given to the possibility of atmospheric methane and nitrogen being of biological origin.

It has also been suggested that life might exist in liquid methane lakes, similar to ground bodies living in water. Such creatures would inhale $\mathrm{H} 2$ instead of $\mathrm{O} 2$, reacting with acetylene instead of glucose and extinguishing methane instead of carbon dioxide. In 2005, astrobiologist Christopher McKay predicted that if methanogenic life consumes atmospheric hydrogen in sufficient volume, it would have a measurable effect on the tropospheric mixing ratio.

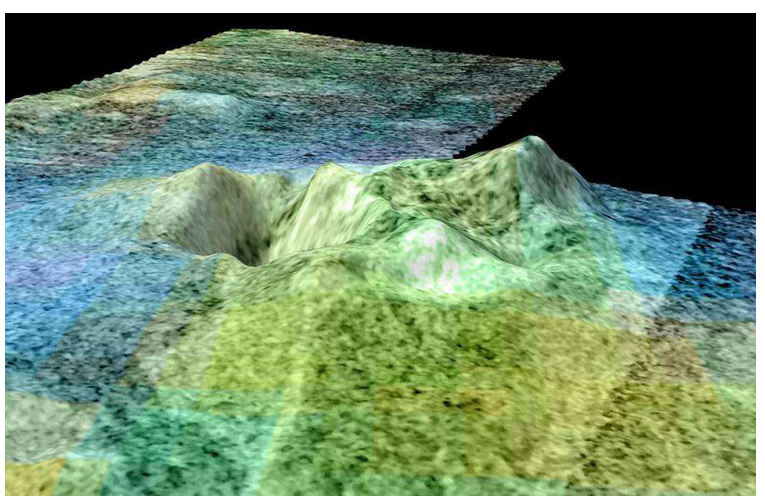

Fig. 7: False VIMS image of a possible Sotra Facula cryovulcan, combined with a 3-D map based on radar data, with peaks of $1,000 \mathrm{~m}$ high and deep craters

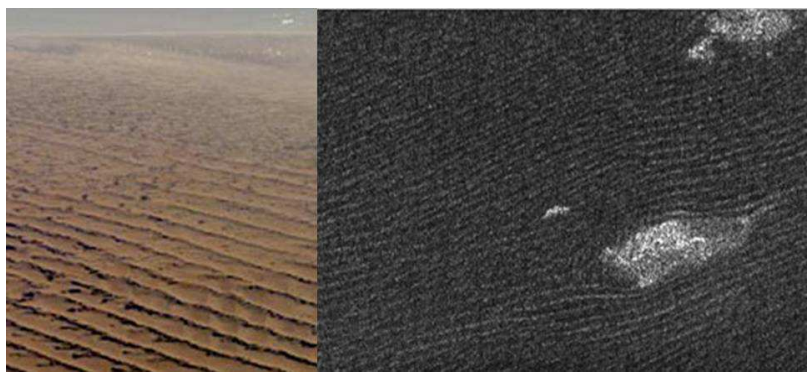

Fig. 8: Sand dune from the Namib Desert, Earth (left), compared to the dunes of Belet, Titan (right)

Evidence of the existence of such a form of life was identified in 2010 by Darrell Strobel of Johns Hopkins University: he noticed a super abundance of molecular hydrogen in the upper layers of the atmosphere, leading to a drop rate of at a rate of 1025 molecules per second. Almost the surface apparently disappears, possibly due to the use of molecular hydrogen by metanogenic life forms. Another paper published in the same month showed evidence of insufficient acetylene on Titan's surface where scientists expected this compound to accumulate; according to Strobel, this consistently confirms the hypothesis that acetylene is consumed by metanogenic life forms. Chris McKay, who agrees that the presence of life is a possible explanation for the presence or absence of hydrogen and acetylene, has warned that other explanations are currently more plausible: the observed results are due to human error or the presence of unknown catalysts on the ground. McKay also said that this catalyst, which would be active at $95 \mathrm{~K}$, would be a surprising discovery in itself.

There is a debate on the efficacy of methane as a living environment compared to water; water is by far a solvent much better than methane because it allows easier transport of substances in a cell, but the lower chemical reactivity of methane makes it easier to form large structures such as proteins. 
So to terrap a planet from our solar system or even from the outside of it, we need to start by creating the atmosphere. Mars's advantage is that it already contains the elements necessary to create the atmosphere of oxygen and hydrogen separated and they can be combined right there to create water on the planet and its atmosphere. Nitrogen, which has the role of atmospheric support, especially for oxygen and atmospheric water, is not found on Mars, so it will have to be created somewhat, which brings some technical difficulties to our current technologies, although they are still in need a future development. On Titan, there is already an atmosphere that contains Azot so that it will need oxygen and a certain amount of water to create an atmosphere identical to Earth. Both elements, oxygen and hydrogen are found in sufficient Titan quantities so we can massively introduce oxygen into Titan's atmosphere to turn it to the ground not by now with about $18-20 \%$ oxygen but at its initial level when oxygen was present in the Earth's atmosphere in massive quantities reaching about $28-30 \%$. Certainly there is already Titan frozen water, but we can also create oxygen and hydrogen for a certain amount to be introduced into the Titanic atmosphere.

The particular aspects of Titan's atmosphere give us a real exuberance that leads us to a possible terrain and colonization of the planet Titan (we can call it the planet, even if it is only a satellite because it has a remarkable dimension).

Despite all these biological possibilities, there are formidable obstacles for Titan's life and any analogy with the Earth is inaccurate. Located at a huge distance from the Sun, Titan is cold and its atmosphere is devoid of $\mathrm{CO} 2$. Because of these difficulties, researchers such as Jonathan I. Lunine regarded the Titan as less a habitat of life, considering it more as an experiment to examine the theories of pre-life conditions on Earth. If life may not exist on Titan, the prebiotic environmental conditions and associated organic chemistry remain of great interest in understanding the early history of the Earth's biosphere. The use of Titan as a prebiotic experiment involves not only observations of space probes but also laboratory experiments and chemical and photochemical modeling of the Earth.

However, it should be borne in mind that an atmosphere composed of oxygen alongside nitrogen could make all of the warmth on the planet much better than it is now. In addition, we can also take into account the hypothesis of the future when our sun as any other star in the universe will begin to age and expand and expand its halo, life on our planet becoming extremely difficult because of the enormous warmth received from the sun in future and life on planets and satellites now farther away from the sun and less heated will then become optimal.

\section{Conclusion}

It is time to move fast and well to study the heavenly bodies of our solar system and not only to begin the action of terrestrial mapping of satellites and planets for the obvious purpose of expanding the human species into the universe.

First of all, we need fast ships, robots with special capabilities to help us in our space missions, new technologies, energy, ultra-fast communication systems, specialized weapons and powerful telescopes, but also of the larger funds allocated by all the states of our planet to these extremely important missions.

So to terrap a planet from our solar system or even from the outside of it, we need to start by creating the atmosphere. Mars's advantage is that it already contains the elements necessary to create the atmosphere of oxygen and hydrogen separated and they can be combined right there to create water on the planet and its atmosphere. Nitrogen, which has the role of atmospheric support, especially for oxygen and atmospheric water, is not found on Mars, so it will have to be created somewhat, which brings some technical difficulties to our current technologies, although they are still in need a future development. On Titan, there is already an atmosphere that contains Azot so that it will need oxygen and a certain amount of water to create an atmosphere identical to Earth. Both elements, oxygen and hydrogen are found in sufficient Titan quantities so we can massively introduce oxygen into Titan's atmosphere to turn it to the ground not by now with about $18-20 \%$ oxygen but at its initial level when oxygen was present in the Earth's atmosphere in massive quantities reaching about $28-30 \%$. Certainly there is already Titan frozen water, but we can also create oxygen and hydrogen for a certain amount to be introduced into the Titanic atmosphere.

The particular aspects of Titan's atmosphere give us a real exuberance that leads us to a possible terrain and colonization of the planet Titan (we can call it the planet, even if it is only a satellite because it has a remarkable dimension).

Despite all these biological possibilities, there are formidable obstacles for Titan's life and any analogy with the Earth is inaccurate. Located at a huge distance from the Sun, Titan is cold and its atmosphere is devoid of $\mathrm{CO} 2$. Because of these difficulties, researchers such as Jonathan I. Lunine regarded the Titan as less a habitat of life, considering it more as an experiment to examine the theories of pre-life conditions on Earth. If life may not exist on Titan, the prebiotic environmental conditions and associated organic chemistry remain of great interest in understanding the early history of the Earth's biosphere. The use of Titan as a prebiotic experiment involves not only observations of space probes but also laboratory experiments and chemical and photochemical modeling of the Earth. 
However, it should be borne in mind that an atmosphere composed of oxygen alongside nitrogen could make all of the warmth on the planet much better than it is now. In addition, we can also take into account the hypothesis of the future when our sun as any other star in the universe will begin to age and expand and expand its halo, life on our planet becoming extremely difficult because of the enormous warmth received from the sun in future and life on planets and satellites now farther away from the sun and less heated will then become optimal.

\section{Acknowledgement}

We acknowledge and thank $\mathrm{Mr}$ Taher M. AbuLebdeh, Associate Prof at North Carolina A and T State Univesity, United States and Mr Muftah H. El-Naas PhD MCIC FICCE QAFCO Chair Professor in Chemical Process Engineering Gas Processing Center College of Engineering Qatar University and Ms Shweta Agarwala, Senior Research Scientist at Singapore Center for 3D Printing Nanyang Technological University Singapore for their suggestions and comments.

\section{Funding Information}

Research contract: Contract number 36-5-4D/1986 from 24IV1985, beneficiary CNST RO (Romanian National Center for Science and Technology) Improving dynamic mechanisms internal combustion engines. All these matters are copyrighted. Copyrights: 548cgiywDssin, from: 22-04-2010, 08:48:48.

\section{Author's Contributions}

All the authors contributed equally to prepare, develop and carry out this manuscript.

\section{Ethics}

This article is original and contains unpublished material. The corresponding author confirms that all of the other authors have read and approved the manuscript and no ethical issues involved.

\section{References}

Aerospace, Technology, 22 DECEMBER 2017 NEWS, Nasa selects concepts for new mission to Saturn's moon Titan, Retrieved from: http://www.aerospacetechnology.com/news/nasa-selects-concepts-newmission-saturns-moon-titan/

Aversa, R., F.I.T. Petrescu, R.V. Petrescu and A. Apicella, 2016a. Biomimetic FEA bone modeling for customized hybrid biological prostheses development. Am. J. Applied Sci., 13: 1060-1067. DOI: 10.3844/ajassp.2016.1060.1067
Aversa, R., D. Parcesepe, R.V. Petrescu, G. Chen and F.I.T. Petrescu et al., 2016b. Glassy amorphous metal injection molded induced morphological defects. Am. J. Applied Sci., 13: 1476-1482.

DOI: 10.3844 /ajassp.2016.1476.1482

Aversa, R., R.V. Petrescu, F.I.T. Petrescu and A. Apicella, 2016c. Smart-factory: Optimization and process control of composite centrifuged pipes. Am. J. Applied Sci., 13: 1330-1341. DOI: 10.3844/ajassp.2016.1330.1341

Aversa, R., F. Tamburrino, R.V. Petrescu, F.I.T. Petrescu and M. Artur et al., 2016d. Biomechanically inspired shape memory effect machines driven by muscle like acting NiTi alloys. Am. J. Applied Sci., 13: 1264-1271. DOI: 10.3844/ajassp.2016.1264.1271

Aversa, R., E.M. Buzea, R.V. Petrescu, A. Apicella and M. Neacsa et al., 2016e. Present a mechatronic system having able to determine the concentration of carotenoids. Am. J. Eng. Applied Sci., 9: 1106-1111. DOI: 10.3844/ajeassp.2016.1106.1111

Aversa, R., R.V. Petrescu, R. Sorrentino, F.I.T. Petrescu and A. Apicella, 2016f. Hybrid ceramo-polymeric nanocomposite for biomimetic scaffolds design and preparation. Am. J. Eng. Applied Sci., 9: 1096-1105. DOI: 10.3844/ajeassp.2016.1096.1105

Aversa, R., V. Perrotta, R.V. Petrescu, C. Misiano and F.I.T. Petrescu et al., 2016g. From structural colors to super-hydrophobicity and achromatic transparent protective coatings: Ion plating plasma assisted $\mathrm{TiO} 2$ and $\mathrm{SiO} 2$ Nano-film deposition. Am. J. Eng. Applied Sci., 9: 1037-1045. DOI: 10.3844/ajeassp.2016.1037.1045

Aversa, R., R.V. Petrescu, F.I.T. Petrescu and A. Apicella, 2016h. Biomimetic and evolutionary design driven innovation in sustainable products development. Am. J. Eng. Applied Sci., 9: 10271036. DOI: 10.3844/ajeassp.2016.1027.1036

Aversa, R., R.V. Petrescu, A. Apicella and F.I.T. Petrescu, 2016i. Mitochondria are naturally micro robots-a review. Am. J. Eng. Applied Sci., 9: 991-1002. DOI: 10.3844/ajeassp.2016.991.1002

Aversa, R., R.V. Petrescu, A. Apicella and F.I.T. Petrescu, 2016j. We are addicted to vitamins $\mathrm{C}$ and E-A review. Am. J. Eng. Applied Sci., 9: 1003-1018. DOI: 10.3844/ajeassp.2016.1003.1018

Aversa, R., R.V. Petrescu, A. Apicella and F.I.T. Petrescu, 2016k. Physiologic human fluids and swelling behavior of hydrophilic biocompatible hybrid ceramo-polymeric materials. Am. J. Eng. Applied Sci., 9: 962-972.

DOI: 10.3844/ajeassp.2016.962.972

Aversa, R., R.V. Petrescu, A. Apicella and F.I.T. Petrescu, 20161. One can slow down the aging through antioxidants. Am. J. Eng. Applied Sci., 9: 1112-1126. DOI: 10.3844/ajeassp.2016.1112.1126 
Aversa, R., R.V. Petrescu, A. Apicella and F.I.T. Petrescu, 2016m. About homeopathy or «Similia similibus curentur $\gg$. Am. J. Eng. Applied Sci., 9: 1164-1172. DOI: 10.3844/ajeassp.2016.1164.1172

Aversa, R., R.V. Petrescu, A. Apicella and F.I.T. Petrescu, 2016n. The basic elements of life's. Am. J. Eng. Applied Sci., 9: 1189-1197. DOI: 10.3844/ajeassp.2016.1189.1197

Aversa, R., F.I.T. Petrescu, R.V. Petrescu and A. Apicella, 2016o. Flexible stem trabecular prostheses. Am. J. Eng. Applied Sci., 9: 1213-1221. DOI: 10.3844/ajeassp.2016.1213.1221

Aversa, R., R.V.V. Petrescu, A. Apicella and F.I.T. Petrescu, 2017a. Nano-diamond hybrid materials for structural biomedical application. Am. J. Biochem. Biotechnol., 13: 34-41. DOI: 10.3844/ajbbsp.2017.34.41

Aversa, R., R.V. Petrescu, B. Akash, R.B. Bucinell and J.M. Corchado et al., 2017b. Kinematics and forces to a new model forging manipulator. Am. J. Applied Sci., 14: 60-80. DOI: 10.3844/ajassp.2017.60.80

Aversa, R., R.V. Petrescu, A. Apicella, I.T.F. Petrescu and J.K. Calautit et al., 2017c. Something about the $\mathrm{V}$ engines design. Am. J. Applied Sci., 14: 34-52. DOI: 10.3844/ajassp.2017.34.52

Aversa, R., D. Parcesepe, R.V.V. Petrescu, F. Berto and G. Chen et al., 2017d. Process ability of bulk metallic glasses. Am. J. Applied Sci., 14: 294-301. DOI: 10.3844/ajassp.2017.294.301

Aversa, R., R.V.V. Petrescu, B. Akash, R.B. Bucinell and J.M. Corchado et al., 2017e. Something about the balancing of thermal motors. Am. J. Eng. Applied Sci., 10: 200.217. DOI: 10.3844/ajeassp.2017.200.217

Berto, F., R.V.V. Petrescu and F.I.T. Petrescu, 2016a. A review of recent results on $3 \mathrm{D}$ effects. Am. J. Eng. Applied Sci., 9:1247-1260.

Berto, F., R.V.V. Petrescu and F.I.T. Petrescu, 2016b. Three-dimensional in bonded joints: A short review. Am. J. Eng. Applied Sci., 9:1261-1268.

Berto, F., A. Gagani, R.V.V. Petrescu and F.I.T. Petrescu, 2016c. Key-hole notches in isostatic graphite: A review of some recent data. Am. J. Eng. Applied Sci., 9: 1292-1300.

Berto, F., A. Gagani, R. Aversa, R.V.V. Petrescu and A. Apicella et al., 2016d. Multiaxial fatigue strength to notched specimens made of 40CrMoV13.9. Am. J. Eng. Applied Sci., 9: 1269-1291.

Mirsayar, M.M., V.A. Joneidi, R.V.V. Petrescu, F.I.T. Petrescu and F. Berto, 2017. Extended MTSN criterion for fracture analysis of soda lime glass. Eng. Fracture Mechan., 178: 50-59. DOI: $10.1016 /$ j.engfracmech.2017.04.018

Petrescu, F.I. and R.V. Petrescu, 2011a. Memories about Flight. 1st Edn., CreateSpace, pp: 652.
Petrescu, F.I. and R.V. Petrescu, 2011b. Mechanical Systems, Serial and Parallel.1st Edn., lulu.com Publisher, London, UK. ISBN-10: 1446600394, pp: 124.

Petrescu, R.V. and F.I.T. Petrescu, 2012a. Northrop. 1st Edn., Books on Demand, ISBN-10: 3848209322 , pp: 142.

Petrescu, F.I. and R.V. Petrescu, 2012b. New Aircraft II. 1st Edn., Books on Demand, pp: 138.

Petrescu, F.I. and R.V. Petrescu, 2012c. MecatronicaSisteme Seriale Si Paralele. 1st Edn., Create Space Publisher, USA, ISBN-13: 978-1-4750-6613-5, pp: 128.

Petrescu, F.I. and R.V. Petrescu, 2012d. Kinematics of the planar quadrilateral mechanism. Engevista, 14: 345-348.

Petrescu, F.I. and R.V. Petrescu, 2016a. Parallel moving mechanical systems kinematics. ENGE-VISTA, 18: 455-491.

Petrescu, F.I. and R.V. Petrescu, 2016b. Direct and inverse kinematics to the anthropomorphic robots. ENGEVISTA, 18: 109-124.

Petrescu, F.I. and R.V. Petrescu, 2016c. Dynamic cinematic to a structure 2R. Revista Geintec-Gestao Inovacao E Tecnologias, 6: 3143-3154.

Petrescu, F.I.T. and J.K. Calautit, 2016a. About nano fusion and dynamic fusion. Am. J. Applied Sci., 13: 261-266.

Petrescu, F.I. and J.K. Calautit, 2016b. About the light dimensions. Am. J. Applied Sci., 13:321-325. DOI: $10.3844 /$ ajassp.2016.321.325

Petrescu, F.I.T., 2009. New aircraft. Proceedings of the 3rd International Conference on Computational Mechanics, Oct. 29-30, Brasov, Romania.

Petrescu, F.I.T., 2012a. Cold Nuclear Fusion. 1st Edn., Create Space, USA, ISBN-10: 1478234261, pp: 80.

Petrescu, F.I.T., 2012b. Particle Annihilation - a Source of Renewable Energy? Infinite Energy Magazine, LuLu Publishers, USA. http://blog.hasslberger.com/2012/02/particle_annihil ation - a sour.html

Petrescu, $\bar{F} . \bar{I} . \bar{T} ., 2016$. Valorificarea Traditiei Ingineresti Romanesti-I: Create Space Publisher, USA. 1st Edn., CreateSpace Independent Publishing Platform, ISBN-10: 1536889946, pp: 152.

Petrescu, R.V. and F.I. Petrescu, 2013a. Lockheed Martin. 1st Edn., CreateSpace, pp: 114.

Petrescu, R.V. and F.I. Petrescu, 2013b. Northrop. 1st Edn., CreateSpace, pp: 96.

Petrescu, R.V. and F.I. Petrescu, 2013c. The Aviation History or New Aircraft I Color. 1st Edn., CreateSpace, pp: 292.

Petrescu, F.I. and R.V. Petrescu, 2013d. Cinematics of the 3R Dyad. Engevista, 15: 118-124.

Petrescu, R.V.V., R. Aversa, A. Apicella, F. Berto and S. Li et al., 2016a. Ecosphere protection through green energy. Am. J. Applied Sci., 13: 1027-1032. 
Petrescu, F.I.T., A. Apicella, R.V.V. Petrescu, S.P. Kozaitis and R.B. Bucinell et al., $2016 \mathrm{~b}$. Environmental protection through nuclear energy. Am. J. Applied Sci., 13:941-946.

Petrescu, R.V., R. Aversa, A. Apicella and F.I. Petrescu, 2016c. Future medicine services robotics. Am. J. Eng. Applied Sci., 9: 1062-1087.

Petrescu, R.V., R. Aversa, B. Akash, F. Berto and A. Apicella et al., 2017a. Forces of a 3R robot. J. Mechatronics Robotics, 1: 1-14.

Petrescu, R.V., R. Aversa, B. Akash, F. Berto and A. Apicella et al., 2017b. Direct geometry and cinematic to the MP-3R systems. J. Mechatronics Robotics, 1: 15-23.

Petrescu, R.V., R. Aversa, B. Akash, F. Berto and A. Apicella et al., 2017c. Dynamic elements at MP3R. J. Mechatronics Robotics, 1: 24-37.

Petrescu, R.V., R. Aversa, B. Akash, F. Berto and A. Apicella et al., 2017d. Geometry and direct kinematics to MP3R with $4 \times 4$ Operators. J. Mechatronics Robotics, 1: 38-46.

Petrescu, R.V., R. Aversa, A. Apicella, M.M. Mirsayar and S. Kozaitis et al., 2017e. Current stage in the field of mechanisms with gears and rods. J. Mechatronics Robotics, 1: 47-57.

Petrescu, R.V., R. Aversa, A. Apicella, M.M. Mirsayar and S. Kozaitis et al., 2017f. Geometry and inverse kinematic at the MP3R mobile systems. J. Mechatronics Robotics, 1: 58-65.

Petrescu R.V., R. Aversa, A. Apicella, M.M. Mirsayar et al., S. Kozaitis et al., 2017g. Synthesis of optimal trajectories with functions control at the level of the kinematic drive couplings. J. Mechatronics Robotics, 1: 66-74.

Petrescu, R.V., R. Aversa, A. Apicella, M.M. Mirsayar and S. Kozaitis et al., 2017h. The inverse kinematics of the plane system 2-3 in a mechatronic MP2R system by a trigonometric method. J. Mechatronics Robotics, 1: 75-87.

Petrescu, R.V., R. Aversa, A. Apicella, M.M. Mirsayar and S. Kozaitis et al., 2017i. Serial, anthropomorphic, spatial, mechatronic systems can be studied more simply in a plan. J. Mechatronics Robotics, 1: 88-97.

Petrescu, R.V., R. Aversa, A. Apicella, M.M. Mirsayar and S. Kozaitis et al., 2017j. Analysis and synthesis of mechanisms with bars and gears used in robots and manipulators. J. Mechatronics Robotics, 1: 98-108.
Petrescu, R.V., R. Aversa, A. Apicella, M.M. Mirsayar and S. Kozaitis et al., 2017k. Speeds and accelerations in direct kinematics to the MP3R systems. J. Mechatronics Robotics, 1: 109-117.

Petrescu, R.V., R. Aversa, A. Apicella, M.M. Mirsayar and S. Kozaitis et al., 20171. Geometry and determining the positions of a plan transporter manipulator. J. Mechatronics Robotics, 1: 118-126.

Williams, D.R., 1995. Saturnian satellite fact sheet. NASA.

https://nssdc.gsfc.nasa.gov/planetary/factsheet/satur niansatfact.html

\section{Source of Figures}

Fig. 1.:

https://photojournal.jpl.nasa.gov/catalog/PIA06230

Fig. 2.:

https://en.wikipedia.org/wiki/Hyperion_(moon)

Fig. 3.:

https://ro.wikipedia.org/wiki/Titan_(satelit)\#/media/File:

Titan_Earth_Moon_Comparison.png

Fig. 4.:

https://ro.wikipedia.org/wiki/Titan_(satelit)\#/media/File: Titan\%27s_Many_Layers.jpg

Fig. 5.:

https://ro.wikipedia.org/wiki/Titan_(satelit)\#/media/File: Titan2005.jpg

https://ro.wikipedia.org/wiki/Titan_(satelit)\#/media/File:

Titan_multi_spectral_overlay.jpg

Fig. 6.:

https://ro.wikipedia.org/wiki/Titan_(satelit)\#/media/File: Titancrater.jpg

Fig. 7.:

https://ro.wikipedia.org/wiki/Titan_(satelit)\#/media/File: Sotra_Facula.jpg

Fig. 8.:

https://ro.wikipedia.org/wiki/Titan_(satelit)\#/media/File: Titan_dunes_crop.png 